\title{
Public e-service development: Understanding citizens' conditions for participation
}

\author{
Jesper Holgersson ${ }^{\text {a }}$, Fredrik Karlsson ${ }^{\mathrm{b}, *}$ \\ a Informatics Research Centre, University of Skövde, SE-541 28 Skövde, Sweden \\ b Informatics, Örebro University School of Business, SE-701 82 Örebro, Sweden
}

\section{A R T I C L E I N F O}

Available online $\mathrm{xxxx}$

\section{Keywords:}

Public e-services

E-government

Public e-service development

User participation

\begin{abstract}
A B S T R A C T
For decades, user participation has brought value to various systems development projects. Today, there are expectations that public e-service development will experience the same benefits. However, existing research has shown that introducing user participation into public e-service development can be challenging. In this study, we interviewed citizens in order to explore their willingness and ability to participate in public e-service development according to three user participation schools: User-Centred Design, Participatory Design and User Innovation. Our findings show that citizens in general are willing to participate, but their ability to do so is limited. Based on our findings, we developed nine propositions to explain citizens' willingness and ability to participate in public e-service development. The propositions contribute to practice by acting as a tentative guide for systems developers when they use user participation schools as inspiration in public e-service projects. They also act as a starting point for future research into conditions for user participation in public e-service development.
\end{abstract}

(c) 2014 Elsevier Inc. All rights reserved.

\section{Introduction}

Information systems are important tools in public administration. Such systems automate manual routines. They also offer citizens and government authorities the opportunity to interact via new channels that are complementary to, or instead of, more traditional interaction channels, such as phone or mail (Lenk, 2002). Lindgren (2013) stated that e-government has three objectives: 1) to improve citizens' opportunities to interact with government authorities, 2) to increase government authorities' efficiency by reducing the number of manual routines, and 3) to increase democracy through greater governmental transparency. However, there is an imbalance between policy and practice regarding these objectives. So far, e-government has primarily been used to automate internal, often manual, routines.

Having said that, e-government is now advancing, moving its focus from internal routines to scenarios in which citizens use public e-services to perform complex transactions with government authorities (Asgarkhani, 2005; Layne \& Lee, 2001), i.e., governmental services that are mediated through the use of information technology (IT) (Lindgren \& Jansson, 2013). Despite this shift in focus, however, government authorities still tend to use IT to reduce costs and the time needed to offer services to citizens and organisations

\footnotetext{
* Corresponding author.

E-mail address: jesper.holgersson@his.se (J. Holgersson).
}

(Anthopoulos, Siozos, \& Tsoukalas, 2007). As a result, public e-services have mainly been developed with a government perspective in mind; other stakeholders' considerations have been given less attention.

Existing e-government research clearly states the importance of acknowledging both internal and external stakeholders during the development of public e-services (Flak \& Rose, 2005; Tan, Pan, \& Lin, 2005). The latter include other government authorities, businesses (Holgersson \& Karlsson, 2012) and, last but not least, citizens (Lindgren, 2013). Citizens pose a challenge, because they constitute a heterogeneous stakeholder group. They may use some public e-services infrequently, such as the tax declarations they make once a year, and have little knowledge of these public e-services. At the same time, they may also be frequent users of other public e-services.

There is increased interest in how to incorporate citizens' views into the development process of public e-services, an interest that is shared by researchers (e.g., Axelsson, Melin, \& Lindgren, 2010; Jones, Hackney, \& Irani, 2007) and practitioners (OECD, 2009). The OECD (2009) has recognised that putting citizen participation into practice is indeed a challenging task. Despite this fact, they strongly encourage citizen participation on the basis that to do otherwise would almost certainly increase the risk of flawed results or project failure. In research, knowledge of citizens' needs and skills is seen as essential for successful public e-service development (e.g., Melin, Axelsson, \& Lundsten, 2008; Verdegem \& Verleye, 2009). Such arguments are not surprising considering earlier experiences of user participation in systems development (Cavaye, 1995; Markus \& Mao, 2004) and long-established recognition of user participation schools 
such as Participatory Design (PD) (e.g., Kensing \& Blomberg, 1998; Mumford, 1981; Schuler \& Namioka, 1993), User-Centred Design (UCD) (e.g., Gulliksen et al., 2003; Iivari \& Iivari, 2011; Norman, 1986) and User Innovation (UI) (e.g., Kujala \& Kauppinen, 2004; Lawrence \& Low, 1993; von Hippel, 1986).

Given these experiences, it is somewhat surprising that user participation and systems development research appears to have had little influence on the e-government field (Karlsson, Holgersson, Söderström, \& Hedström, 2012). Almost all e-government research on user participation has focused on e-participation (e.g., Lourenço \& Costa, 2007; Macintosh, 2006; Sæbø, Rose, \& Skiftenes Flak, 2008). However, exceptions can be found where existing systems development knowledge has been incorporated into public e-service research (Axelsson et al., 2010; Holgersson, Söderström, Karlsson, \& Hedström, 2010; Karlsson et al., 2012). Karlsson et al. (2012) gave a partial response to Jansen's (2006) call to evaluate the applicability of existing user participation schools in e-government projects, such as the development of public e-services. They analysed how the three user participation schools-PD, UCD and UI-fit into the public e-service development context. Their analysis was made from a goal perspective, i.e., what systems developers can expect to achieve by using each of these schools. They identified three challenges related to public e-service development: '1) unclear user target segments can impede the fulfillment of usability and relevance goals; 2 ) the nature of participation can impede the fulfillment of democracy goals, and 3) lack of adequate skills can impede the fulfillment of efficiency goals'.

The first challenge relates to how target users are identified, whereas the latter two challenges focus on citizens' willingness and ability to participate in the development of public e-services. The first challenge is indeed a complex task, and should not be underestimated. However, methods for user identification do exist (Kujala \& Kauppinen, 2004). The second and third challenges, on the other hand, have not been sufficiently addressed. The study by Karlsson et al. (2012) offered a valuable contribution to e-government research. However, this study is based on a literature review, which means we do not know the extent to which these challenges exist in practice. In order to argue for the use of any of the abovementioned user participation schools, citizens' willingness and ability to participate in public e-service development must be analysed using 'real world' data.

Against this backdrop, the aim of this paper is to explore the extent to which citizens are willing and able to fulfill the user-related goals of the three user participation schools-PD, UCD and UI-in the context of public e-service development. Based on 99 semi-structured interviews, we developed a theoretical model. This model puts forward nine propositions to explain citizens' willingness and ability to participate in the development of public e-services according to the prescribed workings of these schools. We chose to address the same user participation schools as Karlsson et al. (2012), even though their goal analysis of user participation research is not without its problems. Contemporary research on user participation (e.g., Marti \& Bannon, 2009) shows that the three schools overlap to some degree. However, by using these three user participation schools, it was possible for us to: (a) base our study on earlier identified goals with user participation, and (b) advance the body of existing research about user participation schools and public e-service development. Our results provide valuable insights into when it is more feasible to apply one form of user participation rather than another. In addition, our theoretical model provides a good starting point for further validation in future research.

The rest of the paper is structured as follows. In the next section we take a closer look at existing user participation schools, and how user participation has been addressed in public e-service research. In the third section we outline the research design. In the fourth section we analyse our empirical data. Following this, in the fifth section, we develop our theoretical model. In the sixth section we discuss implications for research and practice. In addition, we reflect on the limitations of our study and on future research. Finally, the paper ends with a short conclusion.

\section{User participation research and public e-service development}

User participation has long been recognised as an important topic in systems development (e.g., Baroudi, Olson, \& Ives, 1986; Bødker, 1996; Floyd, Mehl, Reisin, Schmidt, \& Wolf, 1989; Hirschheim, 1985; Mumford, 1981). A large number of methods have been promoted which target different conditions (Muller, Hallewell Haslwanter, \& Dayton, 1997). Moreover, as both Mumford (1983) and Heller (1991) have discussed, there are many different arguments for participation, including moral reasons, increased satisfaction, leveraging of power and improved solutions, which can be associated with existing methods. Below, we discuss existing methods, as classified by Karlsson et al. (2012), and show their main arguments.

\subsection{Participatory design, user-centred design and user innovation}

PD has its roots in Scandinavia in the 1970s; in particular, from academia and trade union movements (Marti \& Bannon, 2009). Indeed, much of the early work was carried out in Scandinavia and was explicitly commited to workplace democracy and the politics of design (Bjorn-Andersen \& Hedberg, 1977). The idea was that people affected by an information system should play a critical role in the systems development process. Thus, in projects such as Utopia (Bødker, Ehn, Kammersgaard, Kyng, \& Sundblad, 1987) and Florence (Bjerknes \& Bratteteig, 1988), users and systems developers were viewed as equal partners in the development process. Outside Scandinvia, a different emphasis has been placed on workplace democracy, mostly based on the socio-economic climate (Kensing \& Blomberg, 1998). For example, US researchers pursued PD agendas for other reasons; for example, because of flawed design results (see e.g., Clement, 1994). It was argued that user participation improved 'the knowledge upon which systems are built; enabling people to develop realistic expectations; and reduce resistance to change' (Gregory, 2003). Moreover, during the 1980s, the bargaining power of trade unions decreased throughout Europe and Scandinavia (Kensing \& Blomberg, 1998). Today, PD still entails collaborative partnerships between developers and users, but not for political reasons, as used to be the case. Mumford (1981) described three levels of particpation in PD projects: advisory, representative and consensus. When translated to Arnstein's (1969) ladder of citizen participation, these levels mean that user participation ranges from placation, where citizens' advice is taken into account, to delegated powers where citizens negotiate decisions with the system developers.

UCD emerged in the late 1970s and early 1980s, and is often associated with Norman (1982). Today, UCD principles can be found in the industrial standard Human-centred design processes for interactive systems (ISO 9241-210, 2010). The UCD school implies 'an up-front commitment to taking the needs of the user as the central point for design' (Marti \& Bannon, 2009) and an understanding that information systems are to serve the user (Norman, 1986). The starting point is to understand users' requirements with regard to the user interface; these parts drive other requirements of the information system. Compared with PD, this school places no emphasis on the politics of design; here, systems developers and users are not viewed as equal partners. Indeed, early UCD research (e.g., Kling, 1977) stated that systems developers need to learn about the users' environment in order to understand their needs. Nowadays, however, UCD overlaps PD to a certain extent, because it is possible for users to be seen as 'active agents' (Marti \& Bannon, 2009). This means that, whilst systems developers are the drivers of the development process, users are by no means passive actors. According to Arnstein's (1969) ladder, any user participation in UCD mostly focuses on taking users' advices into consideration (i.e., placation). 
UI refers to innovation by lead users who have strong needs that may be common to other users in the future (von Hippel, 1986). End user development is one type of UI that grew strong during the 1990s, when users were given fourth generation development tools (Sayles, 1990) to frame their daily problems and search for solutions, i.e., to allow them to develop information systems on their own (Taylor, Moynihan, \& Wood-Harper, 1998). Hence, according to Arnstein's (1969) classification of participation, the problem-owners have full control of the development effort. Floyd, Jones, Rathi, and Twidale (2007) showed that this is still a phenomenon. They reported how lead users constructed mash-ups using Web 2.0 and publicly available Application Programming Interfaces (APIs) in order to solve their daily problems and to show systems developers what to build. These types of user innovations have in some cases been disseminated as organisation-wide information systems (Rittenberg \& Senn, 1993). Another example of a UI is userled systems development (Dodd \& Carr, 1994; Lawrence \& Low, 1993). In these cases, lead users act as project leaders of their development teams.

\subsection{Benefits and drawbacks of user participation}

User participation is believed to provide many benefits, including a more complete and accurate definition of requirements (Maiden \& Rugg, 1996), improved work organisation and industrial democracy (Cherry \& Macredie, 1999), improved user interfaces (Smith \& Dunckley, 2002), decreased user resistance to change (Bjerknes \& Bratteteig, 1995), and greater user commitment to implemented systems (Markus, 1983). Despite reported benefits, user participation should not be viewed as a panacea. There are situations where the selected approach has been found to be counterproductive or has been characterised as demanding (McKeen \& Guimaraes, 1997). For example, Wilson, Bekker, Johnson, and Johnson (1996) and Heinbokel, Sonnentag, Frese, Stolte, and Brodbeck (1996) reported that user participation may have negative effects on project performance. Problems can arise when systems developers have to resolve conflicts between user groups or when users demand late changes. Wilson et al. (1996) reported on users and system developers having difficulties in understanding each other, and, sometimes, users have to be educated in what systems development means. In this instance, one should also consider work by Oostveen and van den Besselaar (2004), who found that user participation projects are often characterised as small, standalone applications with low organisational complexity. Moreover, there have been difficulties in sustaining continued use of participative approaches once research interventions have ended. For example, Hirschheim (1983) reported difficulties with the continued use of ETHICS. Consequently, the results of user participation in systems development can be described as inconclusive at best (Cavaye, 1995).

The concept of user participation itself has also been criticised. Hartwick and Barki (1994) argued that it is beneficial to separate user participation from user involvement. They defined the former as 'the behaviours and activities that users or their representatives perform in the system development process'. Consequently, user participation is linked to the kind of abilities users need in order to carry out and filfill the goals of user participation schools. User involvement, on the other hand, is more related to a psychological state. Hartwick and Barki (1994) defined it as "the extent to which a person believes that a system possesses two characteristics, importance and personal relevance'. Hence, user involvement is closely related to what drives users' willingness to carry out an activity, i.e., to participate. We acknowledge this difference through our focus on the concepts of ability and willingness. However, during our study, we used user participation as an all-embracing concept, because it is well established and frequently used in existing research.

\subsection{User participation research in public e-service development}

The number of studies that address user participation in public e-services development is rather limited. Nevertheless, there are some studies in which user participation is discussed in terms of needs and expected value. For example, Tan et al. (2005), Lindgren (2013) and Jones et al. (2007) discussed stakeholder interests in e-government projects. The latter proposed a citizens' research agenda in order to better understand approaches to user engagement, stating that the "key to success of any e-government deployment is the citizen'. Folkerd and Spinelli (2009) added to this discussion by highlighting problems of user exclusion in the requirements engineering stage of e-government development. Moreover, the current definition of the e-government user has widened when compared with earlier definitions, where users were primarily considered to be internal (Følstad, Jørgensen, \& Krogstie, 2004; Oostveen \& van den Besselaar, 2004). Today, external users, such as citizens, are included in the user concept (Jansen, 2006).

Critical reviews of user participation and public e-service development have been carried out by Axelsson et al. (2010), Holgersson et al. (2010) and Karlsson et al. (2012). Axelsson et al. (2010) identified three challenges regarding user participation in public e-service development: 1) e-services need to target 'all of us', 2) citizens need incentives to participate in the development process, and 3) more active forms of user participation are more demanding for the developing organisation. However, they did not discuss how these challenges relate to different user participation schools. Hence, their study did not respond to Jansen's (2006) call to study user participation schools' applicability in a public e-services development context. Holgersson et al. (2010) and Karlsson et al. (2012) partly addressed this gap. They related the goals of three user participation schools to e-service development and sought to identify a set of challenges similar to the ones found by Axelsson et al. (2010). In addition, Holgersson and Karlsson (2012) advanced these results even further by showing that the competence challenges identified by Karlsson et al. (2012) exist in practice. Their results showed that business employees are interested in, and have the mandate to participate in, public e-service development. However, business employees lacked the competences required for working according to 'user participation schools, such as User Innovation, which rely on a high degree of user-responsibility in identifying problems and solutions'. Although business employees are also citizens, these results are not directly transferable; especially when willingness is taken into consideration.

Consequently, we can conclude that there is a vast amount of literature on user participation, spanning more than 30 years. Yet, there is little guidance on what is applicable to the e-government field in general, and public e-service development in particular. As a result, this lack of guidance: (a) complicates practitioners' opportunities to mitigate the lack of user participation in public e-service projects, and (b) reduces opportunities to recommend existing user participation schools when working with a public e-service development project that targets citizens. Consequently, the risk is that the internal (government) perspective remains when public e-services are developed and citizens' considerations are not given the required attention, which in the end will not improve the quality of public e-services.

\section{Research design}

The research method is mainly based on goal analysis (Ågerfalk \& Wistrand, 2003) of user participation schools, interviews (Gillham, 2005; Smith, 1995) and thematic analysis (Braun \& Clarke, 2006; Guest, 2012). Thus, the nine propositions are both theoretically and empirically grounded; theoretically, because they take into account existing goal analyses of user participation schools, and empirically through the interviews. 


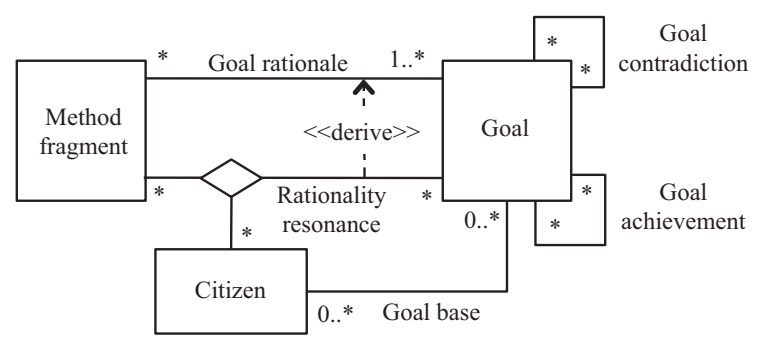

Fig. 1. Modified method rationale framework.

\subsection{Perspective and theoretical framework adapted}

This research draws on work by Karlsson et al. (2012); thus, we view user participation schools from both a systems development method and a design theory perspective. Each school consists of a set of recommended procedures, which are the result of a design activity where certain design goals have been set out (Friedman, 2003). These goals show what a systems developer can expect to achieve when using a specific method (Goldkuhl, Lind, \& Seigerroth, 1997). However, a method also has to fit the current context, otherwise it can hinder more than support the work at hand (Karlsson \& Ågerfalk, 2009). Our interest is, therefore, to study whether or not citizens have the willingness and the ability to fulfill the user-related goals of the three user participation schools.

To achieve this end we used a modified version of the method rationale framework (Ågerfalk \& Wistrand, 2003). The original framework was used by Karlsson et al. (2012) and Holgersson et al. (2010) to structure the goals of the three user participation schools. The modified framework, which is shown in Fig. 1, uses a Unified Modelling Language class diagram. It consists of three classes: method fragment, goal and citizen. Five associations are shown between these classes. The first two classes, method fragment and goal, are found in the original framework. The third class, citizen, is an extension made to facilitate the analysis of citizens' willingness and ability to fulfill the user-related goals of the three user participation schools.

The concept of method fragment refers to a description of a systems development method, or any coherent part thereof (Harmsen, 1997). A method fragment can be studied at five different levels: method, stage, model, diagram and concept. During the analysis we view a user participation school as a stage. In other words, a school is viewed as a section of a systems development method, which in this case, focuses on three aspects of systems development: requirements, analysis and design. Each method fragment is associated with one or more goals that reflect the method's argumentative dimension (Brinkkemper, 1996; Jayratna, 1994). A set of goals reflects the method designer's intentions for a particular method fragment. For example, which goals are related to the use of storyboards in UCD? According to Sutcliffe (2002), at least three goals can be identified: (1) to capture high-level requirements, (2) to test a preliminary design on the users, and (3) to record users' suggestions on redesign. This example shows the goal rationale for the storyboard method fragment. It also shows that a method can have several goals, which either support or contradict each other. In Fig. 1 we illustrated these associations as goal achievements and goal contradictions.

Whether or not a method fragment's goals can be achieved depends on how well they match the method user's willingness and ability to participate. In order to capture these circumstances, we added the concept of the citizen to the framework, together with two associations. First, the goal-base association between the citizen and the goal illustrates the goals held by the citizen in terms of user participation. Second, we inserted an association between method fragment, goal and citizen. This association shows the rationality resonance (Stolterman \& Russo, 1997), i.e., whether or not the goals of a method fragment and citizen's willingness overlap. The derive dependency between the goal association and the rationality resonance association shows that the latter is based on the goals associated with the investigated method fragment.

\subsection{Data collection}

Our analytical framework structured the data collection into three parts, which relate to: 1 ) user participation schools (method fragments), 2) goals associated with the user participation schools, and 3) rationality resonance between the user participation schools' goals and the citizens. With regard to the first two parts, we reused the results of the study by Karlsson et al. (2012). Thus, we used the goals and the goal rationale they identified in relation to UCD, PD and UI. The discussion presented below focuses on the third part, which relates to the capture of rationality resonance.

The respondents were not expected to be able to distinguish between the different user participation schools. Semi-structured interviews (Gillham, 2005; Smith, 1995) were therefore the preferred data collection technique. Through these interviews, different aspects of the schools could be explained to the respondents. The goal analysis put forward by Karlsson et al. (2012) was used as input for the interview guide (Patton, 1990), because rationality resonance can only occur with goals found in the method fragment (cf. 'derive'-dependency in Fig. 1). The interview guide was developed using three steps. First, we classified the goals into two categories: user-related goals or systems developerrelated goals. Our interest in the citizens (users) means that we included the former in the construction of the interview guide. Second, we developed one question for each of the identified goals. The following is an example of a goal that originates from UI: 'Lead users identify the problems'. This goal was turned into the following question: 'Does the respondent experience problems and missing functionality in existing public e-services?' Third, we combined overlapping questions in order to reduce the number of questions to ask the respondents. The complete interview guide, together with the goal mapping, can be found in Appendix A. We tested the interview guide in a pilot study and the findings were published at an international conference (Holgersson \& Karlsson, 2011).

As we have already concluded, user participation in public e-service development is an under-researched area. Thus, this paper is exploratory in nature. It also engages in a data collection strategy that prioritises rich qualitative data in order to increase our understanding over statistically generalisable results. Using a true random sample was not an option, because 'the characteristics under study of the whole population should be known' (Marshall, 1996). This is not the case here. In addition, a nomothetic approach would have been difficult to pursue because of the need for detailed communication with the respondents. In line with case study-based research (Yin, 1994), we can argue that our data allows for generalisations to theoretical constructs (Eisenhardt, 1989; Klein \& Myers, 1999; Lee \& Baskerville, 2003) that relate to rationality resonance between the user participation schools and citizens. These theoretical constructs are presented in Section 5 as a model that consists of nine propositions.

This also meant that we had few criteria for purposive sampling (Silverman, 2010). One can argue that existing extensive research into e-participation (Lourenço \& Costa, 2007; Macintosh, 2006) provides the necessary criteria. However, such participation builds on citizens' willingness and ability to use available public e-services to participate in government activities. Findings are different when considering citizens' willingness and ability to participate in the development of new or updated e-services.

Our study was carried out in Sweden. The pilot study confirmed that citizens have different types of interaction with government during the course of their life. Thus, age was an initial criterion for structuring our sample. We divided the population into six age brackets, as shown in Table 1, with respondents' ages ranging from 18 to 84 years. We used the same age brackets used in official demographic studies in Sweden. 
Table 1

Data collection with regard to age.

\begin{tabular}{ll}
\hline Age interval & Number of respondents \\
\hline $18-29$ & 15 \\
$30-39$ & 21 \\
$40-49$ & 19 \\
$50-59$ & 14 \\
$60-69$ & 15 \\
$70-$ & 15 \\
\hline
\end{tabular}

We did, however, make two exceptions: using ten-year intervals instead of the usual five, and setting a lower age boundary of 18 years, because this is the age at which Swedish citizens are eligible to receive a full e-ID in Sweden without any restrictions.

The selection of respondents was based on a combination of two strategies: convenience sampling (Marshall, 1996) and snowball sampling (Goodman, 1961). First, for the pilot study, we used convenience sampling for each age bracket. Twenty respondents participated in the pilot study. They were identified through: a) formal social networks (e.g., contacting senior citizen associations) and b) the researchers' existing social networks. In practice, this meant that we initially searched for respondents that matched each age bracket, before trying to get an even distribution between participants in each age bracket.

Second, we carried out snowball sampling for this paper, using the initial convenience sampling as a starting point. We asked our initial respondents if they knew other people who may want to participate in the study. In addition, we asked for a short description of these people to make it possible to identify: 1) how they match the age brackets, and 2) extreme cases. With regard to extreme cases, we decided to include respondents who did not currently use computers. We wanted to explore the conditions, if any, under which they were interested in participating in development of public e-services. We did not want to presume that the current non-use of computers, and hence the non-use of public e-services, would necessarily mean that these people would not consider to use such services in the future. Second, we included respondents who use computers a great deal and/or have earlier experiences of information systems development. Indeed, we made a conscious attempt to search for respondents who had enough knowledge about IT to suggest design solutions. In turn, they could act as lead users, which is an important concept in UI. Third, and for the same reason, we also included entrepreneurs among the respondents, because they have skills that are similar to those held by a lead user.

In practice, the selection of respondents was not a mechanical process: potential respondents did not always want to participate in our study or were unavailable. During snowball sampling, we used the principle of 'saturation' (Strauss \& Corbin, 1998) to decide how many new respondents needed to be added to each age bracket. In our case, saturation refers to the point when stable patterns appeared in our analysis of fulfilled or unfulfilled goals in each of the age brackets. Hence, the sampling size of each age bracket varies. The snowball sampling resulted in 79 respondents. In total, 99 interviews were carried out, either face-to-face or by telephone, depending on which was most convenient for the respondent. Each interview lasted approximately $45 \mathrm{~min}$, and all respondents were instructed to answer the questions from a personal perspective.

Our reported findings are based on the respondents' current knowledge of the studied phenomena. One can argue that the respondents' answers are presumptive, as not all respondents have experience of public e-services and/or user participation. However, in a real-world situation, citizens would act on their current experience when asked to participate in a public e-service development project. Hence, their current knowledge would affect both their willingness to participate and their ability to fulfill the goals of the different schools.

\subsection{Data analysis}

Our analysis consisted of three major steps: 1) analysis of respondents' willingness and ability to fulfill the solitary goals of the user participation schools, 2) assignation of respondents to the specific schools based on their overall rationality resonance, and 3 ) thematic analysis of respondents' rationality resonance to create propositions.

We transcribed the interviews before the analysis was carried out. Each interview was classified using the age brackets given in Table 1 . The analysis was then conducted interview question by interview question, because each question can be traced back to the goals of one or more user participation schools. Hence, this analytical step formed an iterative pattern where all user-related goals of the three user participation schools were analysed. For each user statement we asked two questions. What does this say about the respondent's willingness to fulfill the goals associated with this question? What does this statement say about the respondent's abilities to achieve the goals associated with this question? As an example, question $10 \mathrm{E}$ is associated with goal UI-G3 in Karlsson et al. (2012): 'Would you prefer to act as an innovator and cocreator of solutions based on the problems you have experienced when using a particular public e-service?' Our interview transcript from Respondent 30 showed both a lack of willingness and the competence needed to fulfill this goal: 'To put someone like me, who does not use computers at all, to do these things is not feasible. Stop with your crazy ideas would be my response if someone asked me to participate according to this [user participation school]'.

Both authors coded the initial 20 interviews during the pilot study. The first author then carried out the coding of the remaining data. The analysis was carried out continuously throughout the data collection process, in order to keep track of saturation. Thus, the analysis and data collection formed an iterative pattern, which guided the need for further data collection within each age bracket.

When we had completed the analysis of the respondents' rationality resonance, we assigned each respondent to a user participation school. This step was not as straightforward as it may first seem, mainly because a respondent may be willing and able to fulfill solitary goals of more than one school. However, identifying rationality resonance between a solitary goal and a citizen does not mean that there is rationality resonance on an overall level, because each school has several goals. Furthermore, some of the schools share goals. For example, UCD and PD share the goal of 'users as representatives' (cf. UCD-G9 and PD-G7 in Section 4). Therefore, we assigned the respondents to different schools based on the total rational resonance between them and the schools. We also took into consideration whether respondents were both willing and able to fulfill the goals of the school. Concretely, we started analysing respondents' willingness to participate, and, after that, we looked into their ability to fulfill the necessary goals. Consequently, this method of classifying respondents does not rule out the possibility that a respondent has the willingness or the ability to fulfill the solitary goals of another user participation school.

Finally, we carried out a thematic analysis of the respondents' rationality resonance for each of the user participation schools. We categorised the respondents' arguments into a number of themes related to willingness and ability to participate. For example, respondents' arguments for participating (or not participating) according to the different schools were compared to identify similarities and such themes as 'time to participate'. Characteristics were identified for these themes as a step towards identifying various dimensions. For example, a respondent's feeling that they lack the time to participate is a characteristic, which is a possible value on the 'how much time' dimension of proposition P2 (A citizen who lacks time prefers UCD or not to participate at all over PD and UI). These categories served as a foundation for our theoretical model, which consists of nine propositions. This final step of the analysis is presented in the Theoretical model section. 
Table 2

Classification of respondents.

\begin{tabular}{ll}
\hline User participation school & Number of respondents \\
\hline PD & 37 \\
UCD & 42 \\
UI & 2 \\
No participation & 25 \\
\hline
\end{tabular}

\section{Analysis}

The analysis is structured into four subsections, one for each user participation school plus an additional category, termed 'No participation'. We empirically generated the latter to acknowledge that some citizens do not want, or are unable, to fulfill the goals of any of the three user participation schools. This possibility was not discussed by Karlsson et al. (2012). In the presentation below, we use the goal graphs laid out by Karlsson et al. (2012). As discussed earlier, our interest is limited to the user-related goals. These goals are shaded in grey on the goal graphs, whilst the systems developerrelated goals are left unshaded.

Table 2 shows the distribution of respondents between the four categories. We have an overlap of seven respondents who can be placed in both the UCD and PD categories. These respondents were both willing and able to fulfill the goals of both schools. This is natural; the goals of the different schools can overlap each other. Thus, participation in different schools is not mutually exclusive.

\subsection{Participatory design}

Karlsson et al. (2012) identified eleven goals related to PD; these are illustrated in Fig. 3. In terms of the overall goal of PD, they referred to the following statement by Kensing and Blomberg (1998), which identified PD"s aim as: to 'ensure a better fit between technology and way people (want to) perform their work' (PD-G1). As discussed in our section on related research in this paper, this school treats systems developers and users as equal partners. It means that users affected by a decision should also be able to influence that decision (PG-G2). Furthermore, an equal partnership means that systems developers and users have a shared responsibility to cooperate in the development process (Schuler \& Namioka, 1993) through mutual dialogue (Carmel, Whitaker, \& George, 1993; Olphert \& Damodaran, 2007) (PD-G3). By necessity, this shared responsibility means that users need knowledge of possible technical options (PD-G5) (Kensing \& Blomberg, 1998); they also need access to relevant information (PD-G9). Karlsson et al. (2012) went on to stress that users need to be able to take an independent position (PD-G10) with regard to project decisions. On the other hand, system developers need knowledge of the actual context in which the information system will be used (PD-G4).

As shown in Fig. 2, PD has three levels of participation: advisory, representative and consensus. These levels can be traced back to Mumford (1981). They all require that users have a desire to participate in decision making (PD-G11). The advisory level is described as the least demanding. At this level, users respond to specific design decisions presented by the systems developers (PD-G6). The representative level means that users who represent a large group of users participate in the overall design process, rather than specific design decisions (PD-G7). Hence, users can be seen to be closer to having a shared responsibility of the development process. Finally, the consensus level means that all users affected by the design decisions being made work towards a shared agreement (PD-G8).

We identified eight goals that concern users: PD-G3, PD-G5, PD-G6, PD-G7, PD-G8, PD-G9 and PD-G10. However, PD-G9 (user must have access to relevant information) is a goal that cannot be controlled by citizens; therefore, we have not analysed it further.

\subsubsection{Willingness to participate}

We found that respondents who favour PD wanted to play an active part in the development process. This can be illustrated as follows: 'In my opinion the best way to good development is to participate in a proactive manner in the development process', 'I think it is difficult to get a message across in a few single moments and then not have a clue what is happening until it is time to test something, which is almost complete. You have then come long into the development process, making it very difficult to reverse', and 'I think a more continuous interaction is a good idea, but not to the extent that I develop something on my own'.

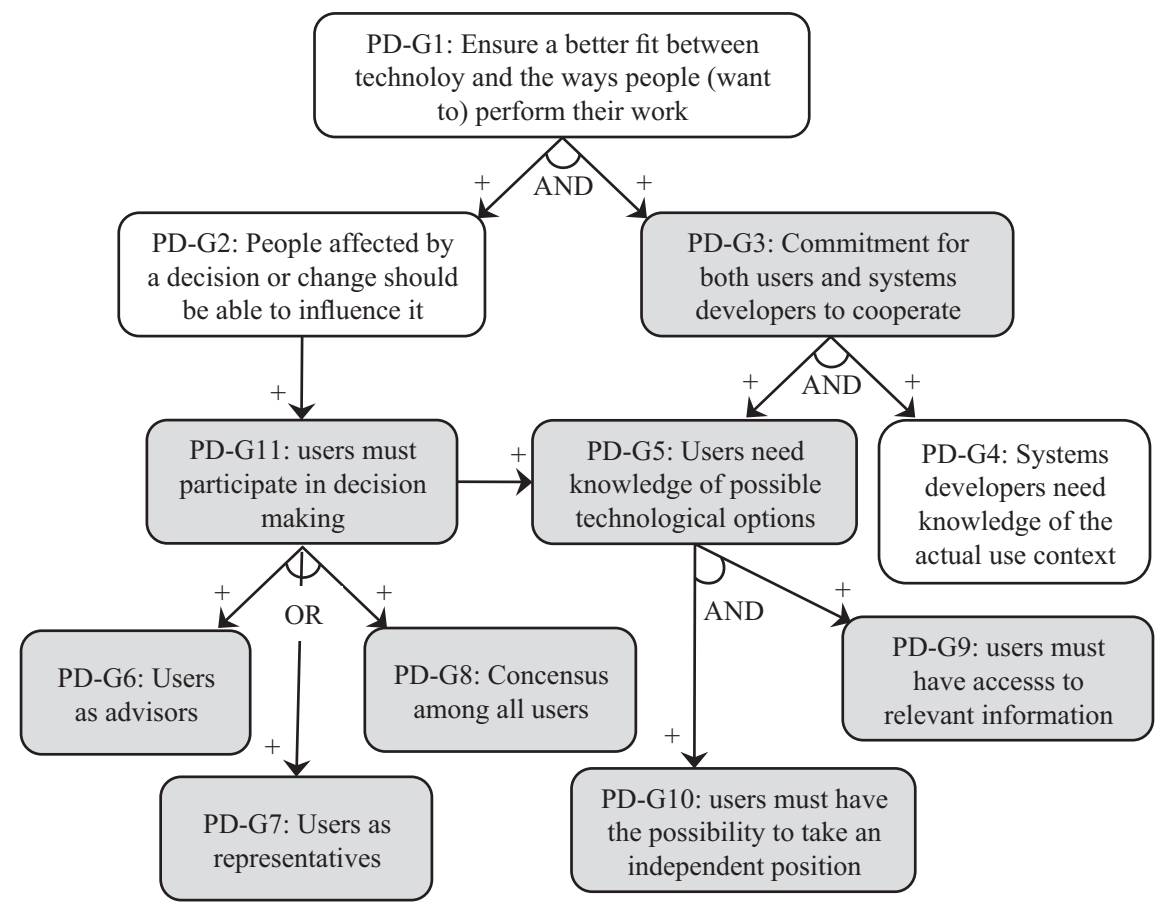

Fig. 2. Goal analysis for PD (Karlsson et al., 2012). 


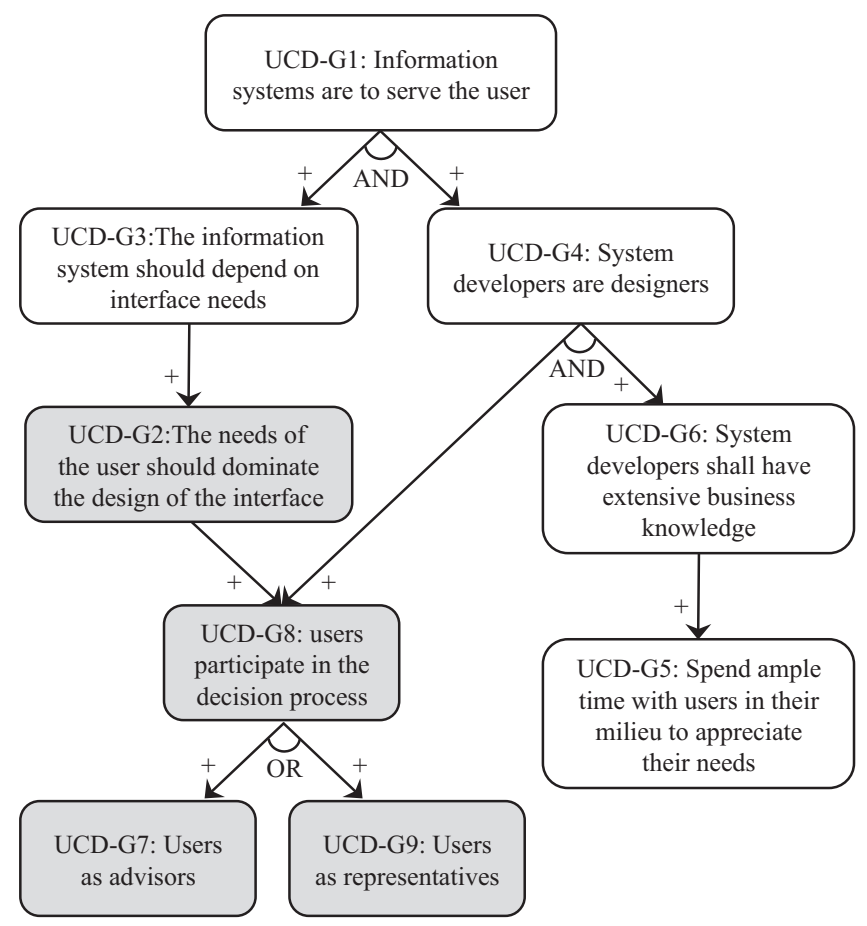

Fig. 3. Goal analysis for UCD (Karlsson et al., 2012).

Respondents who express this view often had an earlier positive experience of participating in systems development projects at work. They favoured participation either as advisors (PD-G6) or representatives (PD-G7). None of the respondents preferred the consensus approach (PD-G8). This is not surprising, because public e-services per se are, in most cases, developed for all citizens, or at least a rather large number of them. A consensus approach with such a large number of users is too complicated to be achieved.

The respondents who favour the advisory role (PD-G6) based their arguments on whether or not the public e-service is familiar to them. For example, two respondents said: 'If you do not use a service you will not see any problems with it either', and 'to participate in development of a service you never use and never will be using would be very odd'. Moreover, the respondents who favour the advisory role wanted to have incentives for participating in the form of a more usable e-service. This is exemplified by the following quote from one of them: 'If I should work [participate in development] with a service I do not use very much I would not participate to the same extent. Those services I use right now are the ones most interesting, so selfish am I'.

The respondents who prefer the representative role (PD-G7) wanted to participate irrespective of whether or not they use the developed e-service. Indeed, their main reason for participation is a strong social commitment. In other words, you should be ready to accept an invitation to participate if you get one. One of the respondents stated that: 'If I can contribute I will do so. I think it is something you get from your parents'. Other reasons to participate as representatives are a general interest in development efforts and curiosity. Respondents who did not gain any personal benefits, needed to have an interest in the development initiative; for example: 'The thing is that I think it is fun to develop things and this has nothing to do with a specific e-service'.

Systems developers and citizens have a shared responsibility to cooperate in the development process (PD-G3). Hence, citizens who favour PD must be willing to take an active part in the development process. Our interviews reveal that the respondents were willing to take this responsibility. Indeed, one of them stated that: 'Direct communication with the developers is probably the best thing'.
Finally, the respondents who belong to the highest age bracket $(70+)$ showed little interest in participating in accordance with the principles of PD. The main reason for this is their modest use of public e-services. The following quote serves as an illustration: 'I do not want to be active, it does not fit me since I do not know so much about eservices'.

\subsubsection{Ability to participate}

With the PD approach, solutions are created through collaboration between systems developers and users. However, systems developers are still responsible for propelling the systems development process forward. Hence, in order to participate, citizens do not need detailed knowledge of technical solutions. Our interviews reveal that respondents who favour PD had necessary knowledge of feasible technological options (PD-G5). They described themselves as being normal or advanced users, which is considered to be sufficient to make basic assessments of design solutions from a user perspective. For example, one of the respondents said: 'Of course I use IT to find information on the Internet, I make applications, I plan my time, I use IT for more or less everything, whatever that might be, I consider myself to be a super user of IT'. Moreover, these respondents used public e-services on a regular basis. Finally, none of our respondents expressed any concerns about taking an independent position during the development of public e-services. This was expected since the study was carried out in Sweden, a country where freedom of speech is part of the constitution. Consequently, PD-G10 is fulfilled.

In summary, the more collaborative form of participation appealed to the respondents who favour PD. They based their arguments on previous positive experience of systems development (PD-F1). Our analysis shows that respondents' willingness to fulfill the goals of PD seems to be driven by: a) personal incentives (PDF2), and b) a strong social commitment and feeling of obligation to participate when called upon (PD-F3). The respondents' usage frequency of a particular public e-service does not seem to increase their willingness to participate further; for example, as representatives. The consensus approach was not favoured by any of the respondents. With respect to IT knowledge, the majority of respondents fulfilled the design goals of PD (PD-F4).

\subsection{User-centred design}

According to Karlsson et al. (2012), UCD has nine main goals, as summarised in Fig. 3. The overall idea of UCD is that the developed system is there to serve the user (UCD-G1). Hence, the development process should be designed to take an 'individual user's capabilities into consideration and fully satisfy his or her needs related to the system to be developed' (Iivari \& Iivari, 2011). Thus, users' needs should dominate the interface design (UCD-G2) (Norman, 1982). Furthermore, the interface requirements are important aspects in determining the functionality and behaviour of the system being developed (UCD-G3) (Iivari \& Iivari, 2011; Norman, 1986).

In early UCD research, developers were promoted as being system designers and builders (UCD-G4). On the other hand, users were seen as passive advisors who respond to the developers' needs (UCD-G7) (Gould \& Lewis, 1985; Kling, 1977). In order for the developers to gain the necessary business knowledge (UCD-G6) they were encouraged to 'spend ample time with the users in their milieu' (UCD-G5) (Kling, 1977). However, Karlsson et al. (2012) argued that, in more recent literature, the user role has evolved, 'by involving the user more directly in the decision process (UCD-G9)'. Both cases show that users participate in the decision process (UCD-G8) (Gulliksen et al., 2003), although to different degrees.

Four of the nine identified goals focus on the user and have been subject to our analysis: UCD-G2, UCD-G7, UCD-G8 and UCD-G9. 


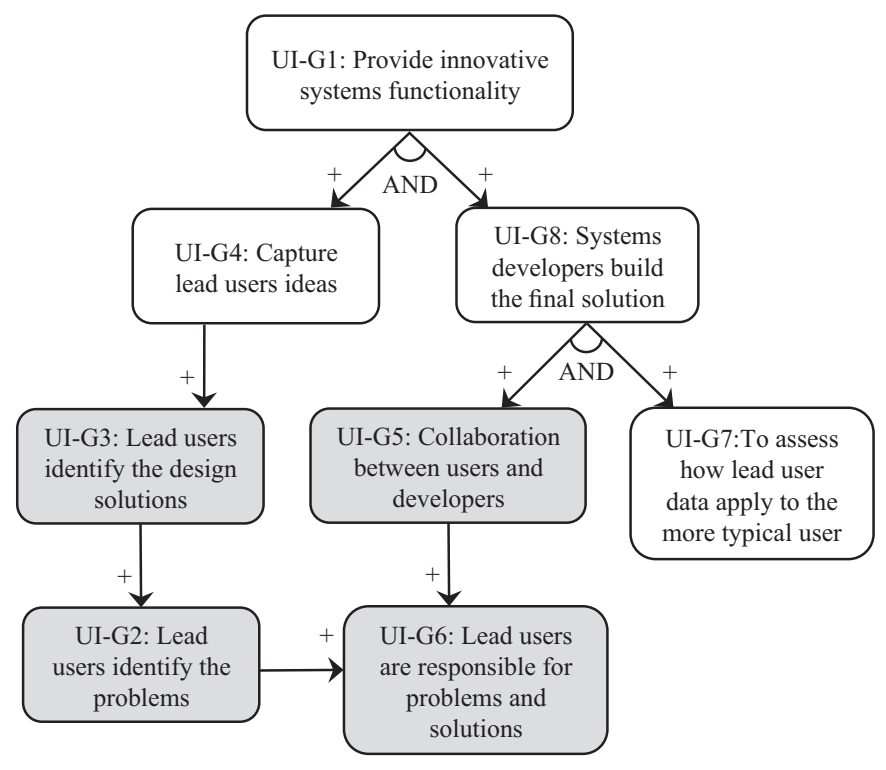

Fig. 4. Goal analysis for user innovation (Karlsson et al., 2012). Four of the eight identified goals focus on the user and have been subject to our analysis: UI-G2, UI-G3, UI-G5, UI-G6.

\subsubsection{Willingness to participate}

We found that citizens in general were positive about participating in the decision process (UCD-G8) according to the principles of UCD. This is illustrated by the following quote from one of the respondents: "The ideal would be to describe the problems I experience ... in the beginning of the work and thereafter pop in the middle of the process in order to not be lost in the end of the process'. Respondents who favour UCD did so because it allows for a passive and reactive form of participation. It is the systems developer who propels the development process forward and makes the final decisions. This is exemplified by the following quotes: 'I would like to be active in the process but on a reasonable level. Not being responsible for things and designing things myself', and 'I am probably at my best in the brainstorming phase. Coming in late and try something out is not really my thing'. We found that the respondents preferred participation as passive advisors (UCD-G7) over participation as more active representatives (UCD-G9). The following quote illustrates this: 'I do not think there is any point to participate more actively, since I do not know very much regarding the development that shall be done. It is better if it is done by those who know this'.

Time was an important factor for the respondents. Citizens who experienced lack of time either did not want to participate or preferred a form of participation that required less participation. From a user perspective, of all the three investigated schools, participation in UCD (UCD-G8) is considered the least demanding. The following quotes from the respondents exemplify this: 'If time was a non-issue, then I would prefer to participate in the whole development process, that is who I am as a person, either $100 \%$ or nothing', 'I would not put any time into participation. If I did participate it would not be very much and the time for it must be reasonable', and 'At the moment I would prefer to participate at a moderate level, I do not think I have time to more than that'.

The respondents' modest experience of using public e-services is another reason why they preferred the design goals of UCD over those of the other two schools. One respondent stated: 'I do not have a computer at home. If I felt like using one I think my children would let me lend theirs. If I use e-services? No, not at all'. Finally, respondents who were satisfied with existing public e-services expressed a preference for UCD. For example: 'I want to participate in accordance with the third option [UCD] .... for me the e-service has been good enough'.

\subsubsection{Ability to participate}

As discussed above, in UCD systems developers are also designers. In terms of participation, UCD is the least demanding school. It is also the least demanding in terms of user qualifications. UCD-G2 in Fig. 2 shows that users should be involved in designing the user interface. In order to do so, citizens must have a basic knowledge of IT, i.e., using computers on a regular basis and making some use of the Internet to find information. The respondents' description of their use of IT shows that a majority of them fulfill these criteria. One of the respondents said: 'I am not a hacker but I am not completely lost either. My brother in law, who works as a systems developer, used to call me a user'. A few of the respondents rated themselves as advanced users, using IT and Internet as an integrated part of their everyday life and building their own applications. Some respondents rated themselves as novice or non-users. It should be noted that they all belong to the age bracket of $70+$ years. Their use of IT and the Internet is infrequent or even absent, as the following quotes indicate: 'I have no computer and I have never had. I do not use IT at all', and 'At the moment I do not have a computer, its broken'. Hence, we can argue that all respondents, except those belonging to the novice or non-user categories, fulfill UCD-G2.

In summary, the respondents who prefer UCD do so for the following reasons: a) lack of time to participate (UCD-F1), b) general satisfaction with existing public e-services (UCD-F2) or c) little or infrequent use of public e-services (UCD-F3). In addition, the respondents tended to favour participation as advisors over participation as representatives. With respect to IT knowledge, the majority of respondents fulfill the goals of UCD (UCD-F4), with the exception of the highest age bracket $(70+$ years $)$.

\subsection{User innovation}

Fig. 4 shows the eight main goals of UI identified by Karlsson et al. (2012). According to them, the overall goal of UI is to provide 'innovative systems functionality' (UI-G1), whereby the users themselves drive innovations. Lead user is therefore a central concept in UI, as described in our earlier section on related research. Karlsson et al. (2012) described the design process as 'an intertwined part of the users' daily work, where products and services are designed and created upon requirements needing to be satisfied'. In practice this means that the lead user both identifies the problems (UI-G2) and designs the solutions (UI-G3). Thus, the lead user is responsible for both (UI-G6) (von Hippel, 1986).

It is important that systems developers analyse and evaluate "how lead user data apply to the more typical user' (von Hippel, 1986) (UIG7), because the lead user's solutions may not necessarily meet the needs of users in general. Therefore, the systems developers' main task is to capture lead users' ideas and designs (UI-G4) and transform them into full-scale solutions in collaboration with the lead users (UI-G5). Consequently, systems developers build the final solution (UI-G8). It means that the final solution might differ in some aspects from the initial design in order to make it work for the general public.

\subsubsection{Willingness to participate}

As is the case for PD, so UI is also based on collaboration between users and systems developers (UI-G5). For UI, however, this collaboration is more intense, because the lead user has responsibility for the initial design. Approximately one third of the respondents expressed a willingness to collaborate with systems developers, using the respondents' ideas as a starting point (UI-G3). Hence, these findings are similar to those for PD. However, our interviews also show that respondents with earlier experience of systems development seem to be more reluctant to engage in more intense collaboration than respondents who lack such experience. The former were aware of the level of commitment needed to accomplish this type of participation and feared that such efforts would consume too much of their time. According to one respondent: 'Yes, I want to make a difference and consider myself to have a little more knowledge than 
others that I could bring to it [the development project]. However, it is a time issue and how much commitment one can put into this'. Based on their previous experience, other respondents feared that systems developers would encourage collaboration without actually following it through. The following respondent expressed this concern: 'It is very important that the government authority listen in a way which is intended from the beginning. If the government then just move along with what they think is important, then everything is wasted'.

Taking the lead users' design ideas as the point of departure is a central aspect of UI. Another aspect is that the lead user has responsibility for problems and solutions (UI-G6). Relatively few of the respondents were willing to take on this responsibility, because they did not want to invest the required time. Thus, some respondents stated: 'If it was a chance to really create improvements and if I had more time, if the day had 48 h instead of 24 , I would gladly take a leading role, always', 'There must be a reasonable timescale for participation', and 'I think it would be interesting but I do not prioritize the time for doing it'.

\subsubsection{Ability to participate}

Approximately half of the respondents identified problems (UI-G2) with public e-services; thus, they had the ability to fulfill UI-G2. These problems mostly concerned a lack of functionality or unclear logic with regard to how to interact with existing public e-services. Some of the respondents identified problems on a general level; for example, the following respondent said: 'At the moment I cannot give any specific example but I often feel that a lot of work is unnecessary complicated and I often think why things cannot be done in a simpler way'. Other respondents were able to be more precise when identifying problems. For example, one respondent said: 'We are supposed to follow our children's attendance at school via their teachers' blog which have replaced papers and other stuff that previously came home. However, there are no links to where these blogs are and you can spend hours trying to find these blogs. All information is on the web but if I do not know the exact correct URL I cannot find it via the municipality's homepage'. The respondents in the highest age bracket $(70+$ years) identified few problems, mainly due to their modest use of public e-services.

Very few respondents were able to propose solutions to the problems they identified, a criteria that is required in order to fulfill UI-G3. One major reason for this is the respondents' lack of knowledge of the way in which government authorities and municipalities work behind the scenes, and the laws and regulations that need to be followed. Several of the respondents who identified possible solutions were well aware of their lack of knowledge in these areas. For example, one respondent said: 'I realise and understand that there are laws and regulations making it hard to accomplish some things' and 'I often wonder how the tax declaration office works. I can question how they work but I have no clue why they do as they do'. However, we also found respondents who did not recognise their shortcomings with respect to this type of knowledge. One respondent said: 'If you look at the health care sector it would be great to have it as in Denmark where you can access all patient records.... A few respondents presented solutions that were grounded in basic knowledge of laws and regulations. These respondents were characterised as frequent users of a specific public e-service and as knowledgeable of a specific government authority. Nonetheless, their proposed solutions resemble problem descriptions. One example is: 'for instance the Swedish Migration Board who demands a certain type of ID [when interacting with the authority via its e-service], which some immigrants cannot get. Immigrants from some countries cannot get these since their IDs are made on typewriters and this is obviously not acceptable for a Swedish authority. Sometimes some things just have to be made outside the preferred way of doing it'. Overall, it means that the respondents were unlikely to satisfy the criteria for UI-G3.

Many of the respondents had earlier experience of systems development, often gained as part of their job. However, in most cases they were instructed to participate and they did not actually drive these projects. Few respondents gave a description of their knowledge of IT and development processes that corresponds to the requirements for actually implementing a design solution. Hence, the respondents had a low level of ability to fulfill UI-G6.

In summary, very few respondents possessed the right combination of knowledge of governmental back office functions (UI-F3), laws and regulations (UI-F4), IT (UI-F5) and systems development (UI-F6) to suggest and design public e-services. It should be noted that this is not the same as saying that these respondents lacked technical skills, e.g., in the area of IT, to qualify as UI candidates. For example, one respondent stated: 'I am a developer, both of my own stuff but also things I have built at the university, where I work to help the IT-department out'. However, in many cases these respondents lacked knowledge of governmental back office functions, and laws and regulations. In addition, our respondents were unwilling to fulfill the goals of UI, because of: a) lack of time (UI-F1), b) earlier negative experience of systems development (UI-F2), or c) a lack of IT knowledge (UI-F3).

\subsection{No participation}

This category is empirically driven and includes respondents who were reluctant or unable to fulfill the goals of the three investigated schools. These respondents gave a lack of time as their main argument, which is illustrated by the following quotes: 'I do not think I would say yes [to participate] if I got the question, it is a matter of time. The days are already so stuffed with everything that should and must be done. When you get a quiet moment to yourself, it is usually late and then it is not possible. And then you do not want one more thing to do', and 'I would say no because I do not want to spend time, but if time was not an issue, I would consider to participate since I think it is needed'.

Low IT maturity also affected the respondents willingness to participate. Often, a lack of IT experience results in a limited use of public eservices. Therefore, respondents tended to believe that they have nothing to contribute. The following quotes exemplified this attitude: 'If I would get such a question [regarding participation] I would say no. There is no point with it since I do not use computers in that way', and 'I am not interested since I use public e-services as little as I do, I feel no commitment to such things when I am not using it'. In addition, a general satisfaction with existing public e-services seemed to reduce the respondents' interest in participating. For example, one respondent stated: 'I am happy as it is right now, I do not feel the need for something else'.

In summary, 'no participation' was a favourable alternative for several of the respondents because of: a) a lack of time to participate (NP-F1), b) infrequent use of public e-services (NP-F2), c) a low level of IT maturity (NP-F3), or d) satisfaction with existing public eservices (NP-F4).

\section{The theoretical model}

The above analysis led us to put forward a theoretical model that consists of nine propositions. The model is divided into two parts: the first part relates to willingness to participate, whilst the second part is concerned with the ability to participate.

\subsection{Willingness to participate}

Our analysis showed that the respondents' satisfaction with current public e-services reduced their willingness to participate more actively (UCD-F2, NP-F4). When respondents were satisfied, they did not see any need to commit themselves to development efforts. Consequently, in such situations, the respondents preferred the UCD school, or to forego participation altogether, over PD and UCD. Thus, our first proposition is that:

P1. A citizen who is satisfied with a public e-service prefers UCD or not to participate at all over PD and UI. 
The second aspect that reduced the respondents' willingness to participate is a lack of time. In these cases the respondents either preferred passive participation or to not participate at all (UCD-F1, UI-F1, NP-F1). Our second proposition is that:

P2. A citizen who lacks time prefers UCD or not to participate at all over PD and UI.

Our analysis showed that respondents who had earlier positive experience of systems development wanted to be continuously involved in the development process (PD-F1). However, our findings also showed that these respondents were unwilling to drive the development process according to the principles of UI (UI-F2). Our third proposition can be formulated as follows:

P3. A citizen with an earlier positive experience of systems development prefers $P D$ over $U C D$ and $U I$.

Our findings also showed that little or infrequent use of public eservices seemed to make the respondents prefer either participation according to UCD or not to participate at all (UCD-F3, NP-F2). Hence, we formulated our forth proposition as follows:

P4. A citizen who infrequently uses public e-services prefers UCD or not to participate at all over PD and UI.

The three user participation schools offer different types of participation. We found that respondents who preferred to be continuously involved as representatives, as prescribed by PD, seem to be driven by a strong social commitment. They also felt obliged to participate when called upon (PD-F3). Respondents who wanted to continuously participate as advisors seem to be driven by personal incentives (PD-F2), e.g., a desire to improve the public e-services they use. Thus, we formulated propositions five and six as:

P5. A citizen with a strong social commitment prefers PD over UCD and UI.

P6. A citizen who has a personal interest in a public e-service prefers $P D$ over UCD and UI.

\subsection{Ability to participate}

Based on the interviews, we found that three aspects affected the respondents' ability to participate in public e-service development: knowledge of public authorities (including knowledge of governmental back office functions, laws and regulations), IT and systems development. We can conclude that the respondents had the ability to fulfill the goals of UCD (UCD-F4), and PD (PD-F4). The main reason is that systems developers are responsible for creating design solutions and propelling the development process forward. In the case of UI, however, this process is more demanding; the citizens themselves have to suggest new design solutions and drive the development process. Few respondents had enough knowledge of IT (UI-F5), or experience of public e-services, to suggest new or improved design solutions. Even fewer respondents possessed enough knowledge of public authorities (UI-F3, UI-F4) to deal with all aspects of a public e-service. In addition, the respondents were not used to driving systems development projects (UI-F6). Hence, propositions seven to nine can be formulated as follows:

P7. Citizens have enough knowledge of public authorities to fulfill the goals of $U C D$ and $P D$.

P8. Citizens have enough knowledge of IT to fulfill the goals of UCD and PD.

P9. Citizens have enough knowledge of systems development to fulfill the goals of $U C D$ and $P D$.

\section{Discussion}

In this study we explored the extent to which citizens are interested in and can fulfill the user-related goals of three user participation schools-PD, UCD and UI-during the development of public e-services. Based on our findings, we presented a theoretical model. Below, we discuss its implications for research and practice.

\subsection{Implications for research}

Existing research on user participation in public e-service development has identified a number of challenges. Axelsson et al. (2010) discussed three challenges that were, to some extent, similar to those put forward by Karlsson et al. (2012). However, whilst Axelsson et al. (2010) based their results on case study findings, they did not address different user participation schools. Karlsson et al. (2012), on the other hand, did address such schools. However, Karlsson et al.'s (2012) discussion was purely theoretical, based entirely on a literature review. In general, our study addresses both these limitations by combining a) a theoretical starting point that incorporates three user participation schools, and b) empirical data from semi-structured interviews with citizens. The resulting theoretical model, which contains nine propositions, advances existing research because it allows for future testing, either in part or as a complete model.

Based on our findings, some notable lessons can be learned with regard to existing research on citizens' abilities and willingness to participate in public e-service development. We found mixed results with regard to their ability to carry out 'the behaviours and activities that users or their representatives perform in the system development process', i.e., user participation according to Hartwick and Barki (1994). Our interviews showed that citizens do not possess enough knowledge of IT, public authorities and systems development to fulfill the goals of UI (H7, H8, H9). Karlsson et al. (2012) and (Holgersson \& Karlsson, 2011) have claimed that citizens have difficulties in fulfilling the goals of UI. We can corroborate these findings, which may not be surprising given the prerequisites needed to propel a systems development process forward. For example, Wilson et al. (1996) have shown that, sometimes, users do not possess the necessary skills to participate in systems development. Thus, they need to be educated if user participation is to be successful.

We found that citizens have enough knowledge of IT, public authorities and systems development to participate according to UCD and PD. These findings might not at first be surprising either, considering that these user participation schools have been in existence for many years (cf. Bjerknes \& Bratteteig, 1988; Bjorn-Andersen \& Hedberg, 1977; Marti \& Bannon, 2009; Norman, 1982). However, many existing studies have focused on internal users. We investigated a situation where the users are external to governmental organisations and have a limited knowledge of governmental work processes, laws and regulations. The PD and UCD schools differ from UI in that citizens do not have responsibility for design and systems developers are the drivers of the systems development process. This simplifies the situation for citizens to participate, from a knowledge point of view. Consequently, it is easier for citizens to fulfill the goals of these schools than to fulfill the goals of UI.

Karlsson et al. (2012) were unable to analyse citizens' willingness to fulfill the goals of the user participation schools. Our findings show that citizens were reluctant to fulfill the goals of UI. First, citizens consider UI to be time consuming (H2) and, second, they seem to be discouraged by earlier negative experiences of user participation in systems development projects (H4). Similar results were also reported by Holgersson and Karlsson (2012), although their study differed in that it involved interviews with business employees. Nonetheless, we can conclude that their findings support our propositions (P2, P3) and that UI is difficult to use, because it is demanding for the users, either as citizens or as business employees. We can conclude that more active forms of user participation, found higher up on Arnstein's (1969) ladder of 
participation, are more demanding for the citizens (cf. our discussion on abilities above). This finding is similar to the conclusion reached by Axelsson et al. (2010), although they reached it from an organisation perspective whereby more active forms of user participation are seen to be more demanding for organisations. We conclude that more active forms of user participation seem to be more demanding for all parties involved.

Hartwick and Barki (1994) argued that user involvement is a psychological state, defined as 'the extent to which a person believes that a system possesses two characteristics, importance and personal relevance'. In line with this view, Axelsson et al. (2010) claimed that incentives are what trigger citizens' willingness to participate. They concluded that we cannot expect citizens to participate if they do not find the developed public e-service meaningful or if they do not think that it makes a difference to them. In general, our findings are in line with their conclusion, that the perceived importance of the developed public e-service affects citizens' willingness to participate. Moreover, we identified preferences for the different schools. Citizens who are satisfied with (P1) or are infrequent users (P4) of public e-services prefer UCD, or do not want to participate at all. Given Hartwick and Barki's (1994) definition and Axelsson et al.'s (2010) results, this finding is not surprising; it seems natural that it is less relevant for citizens to improve a public e-service that they are satisfied with or do not use. Our study also showed that when citizens have personal incentives to improve a public e-service (P5), or a strong social commitment (P6), their willingness to participate according to the PD school increases. Consequently, our propositions (P5, P6) are in line with earlier research, but also include two additional aspects of interest. First, it is not only personal incentives that drive an interest to participate in public e-service development. Citizens want to participate in areas that they are interested in, not only those that make a difference to them personally. Second, our findings showed that these citizens prefer particular schools; PD when the personal incentives are higher, and UCD when they are lower.

\subsection{Implications for practice}

Our theoretical model responds to Jansen's (2006) call for recommendations for user participation schools for public e-service development. The model is based on a limited number of respondents; thus, the results should be interpreted with caution. However, we can still use them to identify tentative implications for practice. As a practical tool the model contains a number of citizen characteristics that need to be taken into consideration when choosing a user participation school. Practitioners can include these characteristics when profiling target groups of public e-services. The model can provide practical guidance on which school is the most favourable given a specific profile. For example, UCD is feasible if the target group includes dissatisfied infrequent users (P4, P1) and PD (as advisors) is favourable if personal incentives can be found (P6).

The theoretical model may also be used as means for identifying suitable participants given a specific development scenario. For example, if UCD, i.e., passive user participation, is a preferred design school, then suitable candidates within the target group must fulfill criteria such as basic IT knowledge and basic familiarity of using e-services. However, they do not need previous experience of systems development. On the other hand, if UI is a desired design school, the target group must fulfill criteria such as the capability to design implementable solutions and a willingness to actively cooperate with systems developers.

Of course, real-world development projects consist of a complex mix of characteristics. Consequently, there might be situations in which criteria contradict each other. For example, we interviewed citizens who are willing to commit themselves to development time-wise but do not use public e-services. In such cases the choice of user participation school must be based on the criteria that can provide the development project with the most useful information.

\subsection{Limitations of this study}

The results are based on a study performed in Sweden. Thus, they may to some extent be limited by this context. Sweden is considered to have a small digital divide in comparison with other industrial countries, such as the UK or Austria (Brandtzæg, Heim, \& Karahasanovic, 2011). Furthermore, Swedish citizens who have previous work-related experience of systems development activities are most likely influenced by the Scandinavian school (Hendry, 2008). In other words, they are used to a high degree of user participation. Together, these factors may affect the result of our study.

An obvious limitation of our study is the limited number of citizens we interviewed, which means that the results cannot be statistically generalised. However, this does not affect the validity of our study, in which interviews were intended as a means to generate theoretical constructs. Thus, this study contributes to the development of a theoretical model that supports choice of a user participation approach for public e-service development.

In addition, we only focused on citizens in this study. As both Tan et al. (2005) and Flak and Rose (2005) showed, citizens are one of several important stakeholder groups. Hence, we acknowledge that the theoretical model does not address their ability and willingness to use any of the three investigated schools during the development of public e-services.

\subsection{Identified areas for future research}

Given the limitations discussed above, there are ample opportunities for future research. First, an interesting avenue for future research is the clear need for a more thorough validation of the theoretical model. One option is to use a quantitative approach, which will give a deeper understanding of the model's generalisability, increasing the model's practical implications. A second avenue of future research is to address the context problem by testing the model in other countries. It may offer an opportunity to identify and study contextual/cultural differences.

\section{Conclusions}

The aim of this paper was to explore the extent to which citizens are willing and have the ability to fulfill the user-related goals of the three user participation schools: Participatory Design (PD), User-Centred Design (UCD) and User Innovation (UI) in the context of public eservice development. To this end we used the theoretical lens of goal analysis. Based on data from semi-structured interviews with citizens, we developed a theoretical model that refers to these three schools to explain the willingness and ability of citizens to participate in public e-service development. In total, the model contains nine propositions that lay down a foundation for further empirical testing. In addition, the propositions may act as a means for choosing the most suitable school given a specific development scenario. For example, according to the model, UCD is more feasible than PD and UI if a public e-service targets inexperienced users. PD on the other hand seems more appropriate when updating an existing e-service with known users who have a personal interest in a public e-service.

Based on the interviews we concluded that, in general, citizens' willingness to participate is high. Factors that affect their degree of willingness to participate are: 1) use of public e-services, 2) satisfaction with public e-services, 3 ) personal incentives, 4) available time, 5) social commitment, and 6) earlier experience of systems development. The ability of citizens to participate is high when considering UCD and PD. However, it is considerably lower when it comes to UI; the main reason is that citizens do not have enough knowledge of how public authorities work. Factors that affect the ability of citizens to participate are: 1) knowledge about public authorities, 2) knowledge about IT, and 3) knowledge about systems development. Finally, the main reason for citizens not to participate is lack of time, often in combination with a low general interest in public e-services. 


\section{Appendix A. Interview guide}

Below we present the semi-interview guide used in this study. Together with the interview guide we give the rationale for why questions were included, and how each question is associated with one or more design goals.

Basic questions for background information regarding the respondent

Questions concerning respondents' background information.

\begin{tabular}{|c|c|}
\hline Question & Rationale \\
\hline $\begin{array}{l}\text { 1. Basic background information about the respondent: } \\
\text { a) Current work tasks? } \\
\text { b) Age? }\end{array}$ & $\begin{array}{l}\text { This question is used to gather basic data about the respondent. It is not related to any of the } \\
\text { design goals but serves as a potential information source when analyzing the interviews. }\end{array}$ \\
\hline $\begin{array}{l}\text { 2. How does the respondent use IT? } \\
\text { a) At home? } \\
\text { b) At work? }\end{array}$ & $\begin{array}{l}\text { This question indicates the extent to which the respondent uses IT and their degree of interest in } \\
\text { IT in general. In turn, this gives an indication of the respondent's IT maturity. } \\
\text { The question was included based on the following design goals: } \\
\text { UCD-G2: The needs of users should dominate the design of the interface. } \\
\text { PD-G5: Users need knowledge of possible technological options. } \\
\text { PD-G9: Users must have access to relevant information. } \\
\text { UI-G2: Lead users identify the problems. } \\
\text { UI-G3: Lead users identify the design solution. }\end{array}$ \\
\hline $\begin{array}{l}\text { 3. Basic knowledge of the e-service concept: } \\
\text { a) What is an e-service and a public e-service for you? } \\
\text { b) Can you exemplify your reasoning? } \\
\text { c) Do you use any specific e-services or public e-services? }\end{array}$ & $\begin{array}{l}\text { This question targets the respondent's current usage of public e-services. It is an important aspect } \\
\text { of being able to identify problems with existing e-services (or lack of e-services) } \\
\text { and possible solutions. The question was included based on the following design goals: } \\
\text { UCD-G2: The needs of the users should dominate the design of the interface. } \\
\text { PD-G5: Users need knowledge of possible technological options. } \\
\text { PD-G9: Users must have access to relevant information. } \\
\text { UI-G2: Lead users identify the problems. } \\
\text { UI-G3: Lead users identify the design solution. }\end{array}$ \\
\hline
\end{tabular}

Personal skills and abilities

Questions concerning respondents' skills and abilities.

\begin{tabular}{|c|c|}
\hline Question & Motive \\
\hline $\begin{array}{l}\text { 4. Does the respondent have earlier experience of project } \\
\text { management? } \\
\text { a) Does the respondent consider himself/herself to be a leader } \\
\text { or a follower and in what situations? }\end{array}$ & $\begin{array}{l}\text { This question addresses the leadership skills of the users, which is important when responsible for identifying } \\
\text { problems with public e-services and designing new solutions. } \\
\text { The question was included based on the following design goals: } \\
\text { UI-G2: Lead users identify the problems } \\
\text { UI-G3: Lead users identify the design solution } \\
\text { UI-G6: Lead users are responsible for problems and solutions. }\end{array}$ \\
\hline $\begin{array}{l}\text { 5. Does the respondent have knowledge about public } \\
\text { authorities' work practices? } \\
\text { a) If possible, can you describe an example of such knowledge } \\
\text { in more detail? }\end{array}$ & $\begin{array}{l}\text { This question focuses on the respondent's knowledge of business processes within public authorities and how IT can } \\
\text { be made part of these processes. The question was included based on the following design goal: } \\
\text { UI-G3: Lead users identify the solution }\end{array}$ \\
\hline
\end{tabular}

Previous experience of systems development and user participation

Questions concerning respondents' previous experience of systems development and user participation.

\begin{tabular}{|c|c|}
\hline Question & Purpose \\
\hline $\begin{array}{l}\text { 6. Does the respondent have any previous experience of participating in systems development? } \\
\text { a) Work related experiences? } \\
\text { b) Other experiences? } \\
\text { c) How would you describe the development work in general? }\end{array}$ & $\begin{array}{l}\text { This question addresses the respondents' knowledge of } \\
\text { systems development } \\
\text { and user participation. This question is not related to any of } \\
\text { the design goals but } \\
\text { indicates the respondents' willingness to participate. }\end{array}$ \\
\hline $\begin{array}{l}\text { 7. Which role best describes the respondent when he/she participated in systems development projects? } \\
\text { (Only considered if the respondent has previous experience of systems development): } \\
\text { a) I have been participating in late stages of the development when most of the work was already done. } \\
\text { b) I have been giving responses to suggested solutions from the systems developers in the early stages of the } \\
\text { development process. } \\
\text { c) I have been actively representing other users, often during a larger part of the development process, and } \\
\text { I have worked together with the systems developers on alternative design solutions. } \\
\text { d) I have been the designer and driving force behind design solutions. I have been collaborating with the systems } \\
\text { developers when implementing these solutions. My ideas have served as the basis for the development work. }\end{array}$ & $\begin{array}{l}\text { This question addresses any previous experiences regarding } \\
\text { user participation } \\
\text { in systems development and may serve as an important } \\
\text { source of information } \\
\text { for the analysis of willingness and ability. The question does } \\
\text { not relate to any of the design goals. }\end{array}$ \\
\hline
\end{tabular}


Willingness and attitudes to user participation in public e-service development

Questions concerning respondents' willingness and attitudes.

\begin{tabular}{|c|c|}
\hline Question & Purpose \\
\hline $\begin{array}{l}\text { 8. If the respondent had previous experience of user participation in systems } \\
\text { development: } \\
\text { What was the reason for participating? } \\
\text { Was participation based on free will or was it part of ordinary work duties? }\end{array}$ & $\begin{array}{l}\text { This question addresses what drives respondents to participate, and how deeply involved } \\
\text { the interviewees want to be. The question was included based on the following design } \\
\text { goals: } \\
\text { UCD-G7: Users as advisors } \\
\text { UCD-G8: Users participate in the decision process } \\
\text { UCD-G9: Users as representatives } \\
\text { PD-G6: Users as advisors } \\
\text { PD-G7: Users as representatives } \\
\text { PD-G8: Consensus among all users } \\
\text { PD-G11: Users must participate in decision making. } \\
\text { UI-G6: Lead users are responsible for problems and solutions. }\end{array}$ \\
\hline $\begin{array}{l}\text { 9. Does the respondent experience problems and missing functionality in existing public } \\
\text { e-services? }\end{array}$ & $\begin{array}{l}\text { This question focuses on the respondents' ability to identify flawed designs. The question } \\
\text { was included based on the following design goal: } \\
\text { UI-G2: Lead users identify the problems }\end{array}$ \\
\hline $\begin{array}{l}\text { 10. Is the respondent interested in participating in public e-service development? If so, } \\
\text { why? Are there any specific situations for preferring one way of participating above } \\
\text { another? } \\
\text { a) Would you prefer to not participate at all? } \\
\text { b) Would you prefer to participate as a tester during the late stages of the development } \\
\text { when most of the work has already been done? } \\
\text { c) Would you prefer to participate mostly during the early stages of the development } \\
\text { process and respond to suggested solutions? } \\
\text { d) Would you prefer to actively represent other users, often during a larger part of the } \\
\text { development process, and work together with the systems developers on alternative } \\
\text { design solutions? } \\
\text { e) Would you prefer to act as an innovator and co-creator of solutions based on the } \\
\text { problems you have experienced when using a particular public e-service? }\end{array}$ & $\begin{array}{l}\text { This question addresses which of the design approaches, if any, the respondents prefer. In } \\
\text { addition, it also address the reasons behind the respondents' preferences. The question } \\
\text { was included based on the following design goals: } \\
\text { UCD-G7: Users as advisors } \\
\text { UCD-G8: Users participate in the decision process } \\
\text { UCD-G9: Users as representatives } \\
\text { PD-G6: Users as advisors } \\
\text { PD-G7: Users as representatives } \\
\text { PD-G8: Consensus among all users } \\
\text { PD-G11: Users must participate in decision making } \\
\text { UI-G2: Lead users identify the problems } \\
\text { UI-G3: Lead users identify the solutions } \\
\text { UI-G5: Collaboration between users and developers } \\
\text { UI-G6: Lead users are responsible for problems and solutions. }\end{array}$ \\
\hline $\begin{array}{l}\text { 11. What kind of challenges do you see with participating in public e-service develop- } \\
\text { ment as a tester of a finished version of a public e-service? }\end{array}$ & $\begin{array}{l}\text { This question addresses the respondents' perceived challenges with design schools that } \\
\text { prescribe user participation in the late stages of the development process. }\end{array}$ \\
\hline $\begin{array}{l}\text { 12. What kind of challenges do you see with participating in the early stages of the } \\
\text { development process and responding to ideas and initiatives from the systems } \\
\text { developers? }\end{array}$ & $\begin{array}{l}\text { This question addresses the respondents' perceived challenges with design schools that } \\
\text { prescribe early user participation and where the systems developer suggests design } \\
\text { solutions. The question was included based on the following design goals: } \\
\text { UCD-G8: Users participate in the decision process } \\
\text { UCD-G7: Users as advisors } \\
\text { UCD-G9: Users as representatives }\end{array}$ \\
\hline $\begin{array}{l}\text { 13. What kind of challenges do you see with participating during a larger part of the } \\
\text { development process, working together with the systems developers? }\end{array}$ & $\begin{array}{l}\text { This question addresses the respondents' perceived challenges with design schools that } \\
\text { prescribe continuously user participation, and where the users and systems developer } \\
\text { collaborate as partners. It was included based on the following design goals: } \\
\text { PD-G5: Users need knowledge of possible technological options } \\
\text { PD-G6: Users as advisors } \\
\text { PD-G7: Users as representatives } \\
\text { PD-G8: Consensus among all users } \\
\text { PD-G9: Users must have access to relevant information } \\
\text { PD-G10: Users must be able to take an independent position } \\
\text { PD-G11: Users must participate in decision making }\end{array}$ \\
\hline $\begin{array}{l}\text { 14. What kind of challenges do you see with participating as an innovator, identifying } \\
\text { problems and suggesting/driving design solutions during the development process? }\end{array}$ & $\begin{array}{l}\text { This question addresses the respondents' perceived challenges with design schools that } \\
\text { prescribe users as the driver of the systems development process. It was included based on } \\
\text { the following design goals: } \\
\text { UI-G2: Lead users identify the problems } \\
\text { UI-G3: Lead users identify the solutions } \\
\text { UI-G6: Lead users are responsible for problems and solutions. } \\
\text { UI-G5: Collaboration between users and developers }\end{array}$ \\
\hline
\end{tabular}

\section{References}

Ågerfalk, P. J., \& Wistrand, K. (2003). Systems development method rationale: A conceptual framework for analysis. Paper presented at the ICEIS 2003, Angers, France.

Anthopoulos, L. G., Siozos, P. S., \& Tsoukalas, I. A. (2007). Applying participatory design and collaboration in digital public services for discovering and re-designing eGovernment services. Government Information Quarterly, 24(2), 353-376.

Arnstein, S. R. (1969). A ladder of citizen participation. Journal of the American Planning Association, 35(4), 216-224.

Asgarkhani, M. (2005). The effectiveness of e-Service in local government: A case study. Electric Journal of e-Government, 3(4), 157-166.

Axelsson, K., Melin, U., \& Lindgren, I. (2010). Exploring the importance of citizen participation and involvement in e-government projects-Practice, incentives and organization. Transforming Government: People, Process and Policy, 4(4), 299-321.

Baroudi, J. J., Olson, M. H., \& Ives, B. (1986). An empirical study of the impact of user involvement on system usage and information satisfaction. Communications of the ACM, 29(3), 232-238.

Bjerknes, G., \& Bratteteig, T. (1988). The memoirs of two survivors: Or the evaluation of a computer system for cooperative work. In I. Greif (Ed.), Proceedings of the 1988 ACM conference on Computer-supported cooperative work (pp. 167-177). New York, NY, USA: ACM.

Bjerknes, G., \& Bratteteig, T. (1995). User participation and democracy: A discussion of Scandinavian research on system development. Scandinavian Journal of Information Systems, 7(1), 73-98.

Bjorn-Andersen, N., \& Hedberg, B. (1977). Designing information systems in an organisational perspective. Studies in the Management Science: Prescriptive Models of Organisations, 5(1977), 125-142.

Bødker, S. (1996). Creating conditions for participation: Conflicts and resources in systems development. Human Computer Interaction, 11(3), 215-236. 
Bødker, S., Ehn, P., Kammersgaard, J., Kyng, M., \& Sundblad, Y. (1987). A Utopian experience. In G. Bjerknes, P. Ehn, \& M. Kyng (Eds.), Computers and democracy: A Scandinavian challenge (pp. 251-278). Avebury, UK: Aldershot.

Brandtzæg, P. B., Heim, J., \& Karahasanovic, A. (2011). Understanding the new digital divide-A typology of Internet users in Europe. International Journal of HumanComputer Studies, 69(3), 123-138.

Braun, V., \& Clarke, V. (2006). Using thematic analysis in psychology. Qualitative Research in Psychology, 3(2), 77-101.

Brinkkemper, S. (1996). Method engineering: Engineering of information systems development methods and tools. Information and Software Technology, 38(4), 275-280.

Carmel, E., Whitaker, R. D., \& George, J. F. (1993). PD and joint application design: A transatlantic comparison. Communications of the ACM, 36(6), 40-48.

Cavaye, A. L. M. (1995). User participation is systems development revisited. Information and Management, 28(5), 311-323.

Cherry, C., \& Macredie, R. D. (1999). The importance of context in information system design: An assessment of participatory design. Requirements Engineering 4(2), 103-114.

Clement, A. (1994). Computing at work: Empowering action by 'low-level users'. Communications of the ACM, 37(1), 52-65.

Dodd, J. L., \& Carr, H. H. (1994). Systems development led by end-users: An assessment of end-user involvement in information systems development. Journal of Systems Management, 45(8), 34-40.

Eisenhardt, K. (1989). Building theories from case study research. Academy of Management Review, 14(4), 532-550.

Flak, L. S., \& Rose, J. (2005). Stakeholder governance: Adapting stakeholder theory to eGovernment. Communications of the Association for Information Systems, 16, 641-664.

Floyd, I. R., Jones, M. C., Rathi, D., \& Twidale, M. B. (2007). Web mash-ups and patchwork prototyping: User-driven technological innovation with Web 2.0 and Open Source Software. Paper presented at the 40th Hawaii International Conference on Systems Sciences, Waikoloa, Big Island, Hawaii.

Floyd, C., Mehl, W. -M., Reisin, F. -M., Schmidt, G., \& Wolf, G. (1989). Out of Scandinavia: Alternative approaches to software design and system development. Human Computer Interaction, 4(4), 253-350.

Folkerd, C., \& Spinelli, G. (2009). User exclusion and fragmented requirements capture in publicly-funded IS projects. Transforming Government: People, Process and Policy, 3(1), 32-49.

Følstad, A., Jørgensen, H. D., \& Krogstie, J. (2004). User involvement in e-government development projects. Paper presented at the third Nordic conference on Human-computer interaction, Tampere, Finland.

Friedman, K. (2003). Theory construction in design research: Criteria, approaches, and methods. Design Studies, 24, 507-522.

Gillham, B. (2005). Research interviewing: The range of techniques. Maidenhead, England: McGraw-Hill International.

Goldkuhl, G., Lind, M., \& Seigerroth, U. (1997). Method integration as a learning process. In N. Jayaratna, B. Fitzgerald, J. -M. Larrasquet, P. Checkland, E. Mumford, \& T. WoodHarper (Eds.), Training and Education of Methodology Practitioners and Researchers: 5th International Conference of the British Computer Society Information System Methodologies Specialist Group (pp. 15-26). Preston, UK: Springer.

Goodman, L. A. (1961). Snowball sampling. Annals of Mathematical Statistics, 32(1), $148-170$.

Gould, J. D., \& Lewis, C. (1985). Designing for usability: Key principles and what designers think. Communications of the ACM, 28(3), 300-311.

Gregory, J. (2003). Scandinavian approaches to participatory design. International Journal of Engineering Education, 19(1), 62-74.

Guest, G. (2012). Applied thematic analysis. London: SAGE Publications, Inc.

Gulliksen, J., Göransson, B., Boivie, I., Blomkvist, S., Persson, J., \& Cajander, Å. (2003). Key principles for user-centred systems design. Behaviour \& Information Technology, 22(6), 397-409.

Harmsen, F. (1997). Situational method engineering. Utrechts, Netherlands: Moret Ernst \& Young Management Consultants.

Hartwick, J., \& Barki, H. (1994). Explaining the role of user participation in information system use. Management Science, 40(4), 440-465.

Heinbokel, T., Sonnentag, S., Frese, M., Stolte, W., \& Brodbeck, F. C. (1996). Don't underestimate the problems of user centredness in software development projects \pm there are many! Behaviour \& Information Technology, 15(4), 226-236.

Heller, F. (1991). Participation and competence: A necessary relationship. In R. Russel, \& V. Rus (Eds.), International handbook of participation in organizations. New York: Oxford University Press

Hendry, D. G. (2008). Public participation in proprietary software development through user roles and discourse. Information Systems Journal, 66(7), 545-557.

Hirschheim, R. (1983). Assessing participative systems design: Some conclusions from an exploratory study. Information Management, 6(6), 317-327.

Hirschheim, R. (1985). User experience with and assessment of participative system design. MIS Quarterly, 9(4), 295-304.

Holgersson, J., \& Karlsson, F. (2011). Exploring citizens' possibilities to participate in public e-service development. In J. -L. Chappelet, O. Glassey, M. Janssen, A Macintosh, J. Scholl, E. Tambouris, \& M. A. Wimmer (Eds.), Joint Proceedings of Ongoing Research and Projects of IFIP EGOV and ePart 2010 (pp. 83-91). Linz: Trauner Verlag.

Holgersson, J., \& Karlsson, F. (2012). Understanding business employees' conditions for participating in public e-service development. ECIS 2012 Proceedings (paper 24). Barcelona, Spain: AIS Electronic Library (AISeL) (Barcelona, Spain).

Holgersson, J., Söderström, E., Karlsson, F., \& Hedström, K. (2010). Towards a roadmap for user involvement in e-government service development. In M. A Wimmer, J. -L. Chappelet, M. Janssen, \& H. J. Scholl (Eds.), Electronic Government, 9th IFIP WG 8.5 International Conference, EGOV 2010, Vol. 6228. (pp. 251-262). Berlin: Springer.
Iivari, J., \& Iivari, N. (2011). Varieties of user-centredness: An analysis of four systems development methods. Information Systems Journal, 21(2), 251-262.

ISO (2010). Ergonomics of human-system interaction-Part 210: Human-centred design for interactive systems. Geneva: International Organization for Standardization.

Jansen, A. (2006). Strategies for user involvement in eGovernment projects: What can be learned from the Scandinavian IS tradition? Paper presented at the NordiCHI'06 Workshop on User involvement and representation in e-Government projects, Oslo.

Jayratna, N. (1994). Understanding and evaluating methodologies. London: McGraw-Hill.

Jones, S., Hackney, R., \& Irani, Z. (2007). Towards e-government transformation: Conceptualising "citizen engagement". Transforming Government: People, Process and Policy, 1(2), 145-152.

Karlsson, F., \& Ågerfalk, P. J. (2009). Towards structured flexibility in information systems development: Devising a method for method configuration. Journal of Database Management, 20(3), 51-75.

Karlsson, F., Holgersson, J., Söderström, E., \& Hedström, K. (2012). Exploring user participation approaches in public e-service development. Government Information Quarterly, 29(2), 158-168.

Kensing, F., \& Blomberg, J. (1998). Participatory design: Issues and concerns. Computer Supported Cooperative Work, 7(3-4), 167-185.

Klein, H. K., \& Myers, M. D. (1999). A set of principles for conducting and evaluating interpretive field studies in information systems. MIS Quarterly, 23(1), 67-94.

Kling, R. (1977). The organizational context of user-centered software designs. MIS Quarterly, 1(4), 41

Kujala, S., \& Kauppinen, M. (2004). Identifying and selecting users for user-centered design. Paper presented at the Third Nordic conference on Human-computer interaction, Tampere, Finland.

Lawrence, M., \& Low, G. (1993). Exploring individual user satisfaction within user-led development. MIS Quarterly, 17(2), 195-208.

Layne, K., \& Lee, J. (2001). Developing fully functional E-government: A four stage model. Government Information Ouarterly, 18(2), 122-136.

Lee, A. S., \& Baskerville, R. (2003). Generalizing generalizability in information system research. Information Systems Research, 14(3), 221-243.

Lenk, K. (2002). Electronic Service Delivery-A driver of public sector modernization. Information Polity, 7(2-3), 87-96.

Lindgren, I. (2013). A study on who matters for public e-service development and implementation. Linköping, Sweden: Linköping University.

Lindgren, I., \& Jansson, G. (2013). Electronic services in the public sector: A conceptual framework. Government Information Quarterly, 30(2), 163-172.

Lourenço, R. P., \& Costa, J. P. (2007). Incorporating citizens' views in local policy decision making processes. Decision Support Systems, 43(4), 1499-1511.

Macintosh, A. (2006). eParticipation in policy-making: the research and the challenges. In P. Cunningham, \& M. Cunningham (Eds.), Exploiting the knowledge economy: Issues, applications and case studies (pp. 364-369). Amsterdam: IOS Press.

Maiden, N. A. M., \& Rugg, G. (1996). ACRE: Selecting methods for requirements acquisition. Software Engineering Journal, 11(3), 183-192.

Markus, M. L. (1983). Power, politics and MIS implementation. Communications of the ACM, 26(6), 430-444.

Markus, M. L., \& Mao, J. -Y. (2004). Participation in development and implementationUpdating an old, tired concept for today's IS contexts. Journal of Association of Information Systems, 5(11-12), 514-544.

Marshall, M. N. (1996). Sampling for qualitative research. Family Practice, 13(6), 522-525.

Marti, P., \& Bannon, L. J. (2009). Exploring user-centred design in practice: Some caveats. Knowledge, Technology \& Policy, 22(1), 7-15.

McKeen, J. D., \& Guimaraes, T. (1997). Successful strategies for user participation in systems development. Journal of Management Information Systems, 14(2), 133-150.

Melin, U., Axelsson, K., \& Lundsten, M. (2008). Talking to, not about, entrepreneurs-Experiences of public e-service development in a business start up case. Paper presented at the eChallanges, Stockholm, Sweden.

Muller, M. J., Hallewell Haslwanter, J., \& Dayton, T. (1997). Participatory practices in the software lifecycle. In M. Helander, T. K. Landauer, \& P. Prabhu (Eds.), Handbook of human-computer interaction (pp. 255-297). Amsterdam: Elsevier.

Mumford, E. (1981). Participative systems design: Structure and method. Systems, Objectives, Solutions, 1(1), 5-19.

Mumford, E. (1983). Designing human systems for new technology, The ETHICS method. Manchester: Manchester Business School.

Norman, D. (1982). Steps toward a cognitive engineering: Design rules based on analyses of human error. Paper presented at the Human factors in computing systems, New York

Norman, D. (1986). Cognitive engineering. In D. A. Norman, \& S. W. Draper (Eds.), Usercentered system design: new perspectives on human computer interaction (pp. 31-65). London: Lawrence Erbaum Associated.

OECD (2009). Focus on citizens: Public engagement for better policy and services. OECD.

Olphert, W., \& Damodaran, L. (2007). Citizen participation and engagement in the design of e-government services: The missing link in effective ICT design and delivery Journal of the Association for Information Systems, 8(9), 491-507.

Oostveen, A. -M., \& van den Besselaar, P. (2004). From small scale to large scale user participation: A case study of participatory design in e-government systems. Paper presented at the Participatory Design Conference, Toronto, Canada.

Patton, Michael Quinn (1990). Qualitative evaluation and research methods. Newbury Park CA: Sage.

Rittenberg, L. E., \& Senn, A. (1993). End-user computing. The Internal Auditor, 50(1), 35-40.

Sæbø, Ø., Rose, J., \& Skiftenes Flak, L. (2008). The shape of eParticipation: Characterizing an emerging research area. Government Information Quarterly, 25(3), 400-428.

Sayles, J. (1990). Beware the dark side of 4GLs. Computerworld, 24(35), 100.

Schuler, D., \& Namioka, A. (1993). Participatory design principles and practices-Preface. In D. Schuler, \& A. Namioka (Eds.), Participatory design principles and practices. London: Lawrence Erlbaum Associates Inc. 
Silverman, D. (2010). Doing qualitative research: A practical handbook. London: Sage. Smith, J. A. (1995). Semi-structured interviewing and qualitative analysis. In J. A. Smith, R. Harré, \& L. V. Langenhove (Eds.), Rethinking methods in psychology. London: Sage.

Smith, A., \& Dunckley, L. (2002). Prototype evaluation and redesign: Structuring the design space through contextual techniques. Interacting with Computers, 14(6), 821-843.

Stolterman, E., \& Russo, N. L. (1997). The paradox of information systems methods-Public and private rationality. Paper presented at the British Computer Society 5th Annual Conference on Methodologies, Lancaster, England.

Strauss, A. L., \& Corbin, J. M. (1998). Basics of qualitative research: Techniques and proce dures for developing grounded theory (2nd ed.). Thousand Oaks, CA.: Sage.

Sutcliffe, A. (2002). User-centred requirements engineering-Theory and practice. London: Springer-Verlag.

Tan, C. -W., Pan, S. L., \& Lin, E. T. K. (2005). Managing stakeholder interests in egovernment implementation: Lessons learned from a Singapore e-government project. Journal of Global Information Management, 13(1), 31-53.

Taylor, M. J., Moynihan, E. P., \& Wood-Harper, A. T. (1998). End-user computing and information systems methodologies. Information Systems Journal, 8(1), 85-96.

Verdegem, P., \& Verleye, G. (2009). User-centered e-government in practice: A comprehensive model for measuring user satisfaction. Government Information Quarterly, 26(3), 487-497. von Hippel, E. (1986). Lead users: A source of novel product concepts. Management Science, 32(7), 791-805.

Wilson, S., Bekker, M., Johnson, H., \& Johnson, P. (1996). Costs and benefits of user involvement in design: Practitioners' Views. In M. A. Sasse, J. Cunningham, \& R. L. Winder (Eds.), Proceedings of HCI on People and Computers X (pp. 221-240). London: Springer-Verlag.

Yin, R. K. (1994). Case study research: Design and methods. Thousand Oaks, CA: Sage.

Fredrik Karlsson is Professor in Information Systems at Örebro University. He has previously held a research position at University of Skövde. He received his PhD in Information Systems Development from Linköping University. His research on tailoring of systems development methods, system development methods as reusable assets, CAME-tools, electronic government and information security has appeared in a variety of information systems journals and conferences. He is currently Deputy Head of Örebro University School of Business.

Jesper Holgersson is a PhD student and a teacher at the University of Skövde. He received a masters degree from University of Skövde 2002. His research mainly concerns user participation in e-service development, particularly e-services used in public settings. 